\title{
Memória, identidade e representação: Os limites da teoria e a construção do testemunho
}

Memory, Identity and Representation: The Limits of Theory and the

Construction of Testimony

Mémoire, identité et représentation: les limites de la théorie et la construction du témoignage

\section{António Sousa Ribeiro}

\section{(2) OpenEdition}

\section{Journals}

Edição electrónica

URL: http://journals.openedition.org/rccs/1689

DOI: $10.4000 /$ rccs. 1689

ISSN: 2182-7435

\section{Editora}

Centro de Estudos Sociais da Universidade de Coimbra

\section{Edição impressa}

Data de publição: 1 Março 2010

Paginação: 9-21

ISSN: 0254-1106

\section{Refêrencia eletrónica}

António Sousa Ribeiro, « Memória, identidade e representação: Os limites da teoria e a construção do testemunho », Revista Crítica de Ciências Sociais [Online], 88 | 2010, colocado online no dia 01 outubro 2012, criado a 20 abril 2019. URL : http://journals.openedition.org/rccs/1689 ; DOI : 10.4000/ rccs. 1689

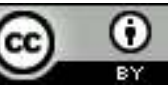




\title{
ANTÓNIO SOUSA RIBEIRO
}

\section{Memória, identidade e representação: Os limites da teoria e a construção do testemunho}

\begin{abstract}
Partindo da perspectiva de que a teoria do Holocausto oferece um quadro paradigmático susceptível de fundar uma reflexão global sobre os fenómenos de violência extrema na modernidade, revisita-se a questão do significado do Holocausto para a compreensão das possibilidades e dos limites de reconstrução de identidades em contextos pós-traumáticos. Acentua-se, em especial, o papel do testemunho como espaço de tradução conducente à superação do estatuto de vítima e à afirmação de uma memória e uma pós-memória públicas.
\end{abstract}

Palavras-chave: genocídio; Holocausto; identidade; justiça; memória; testemunho; trauma; violência; vítimas.

Enquanto signo de uma "ruptura civilizacional" irreparável (Diner, 1988), Auschwitz tornou-se, na reflexão contemporânea, a metáfora central para designar todo o complexo de experiências originadas em situações marcadas por formas extremas de violência. É assim que o Holocausto continua a ser uma referência absolutamente paradigmática para quem, nos mais diferentes contextos, pretenda analisar as possibilidades e limites da reconstrução da identidade no quadro de uma memória pós-traumática. Apesar disso, muitas vezes e em vários contextos se colocou a questão de saber se o Holocausto foi um acontecimento verdadeiramente singular. Trata-se de uma questão que tem feito correr rios de tinta e que está longe de ser inocente. Como pudemos ver, nomeadamente, nos anos oitenta na Alemanha em torno da chamada disputa dos historiadores (Historikerstreit), a negação da singularidade do genocídio nazi resvala facilmente para uma dimensão com contornos apologéticos e visa muitas vezes um objectivo relativizador. Para o historiador Ernst Nolte, o principal porta-voz da facção relativizadora, era tempo de pôr ponto final na culpabilização dos alemães pelo Holocausto, já que horrores idênticos podiam ser imputados, por exemplo, à repressão estalinista. Mais até, para este autor, a verdadeira explicação histórica do 
Holocausto estaria na existência do Gulag - o terror nazi mais não seria do que uma reacção ao terror estalinista. Teses como esta são insustentáveis e, logo na altura, foram cabalmente refutadas. ${ }^{1}$ No entanto, perante as várias experiências de violência em larga escala ao longo do século Xx, a tentativa de encarar o genocídio nazi como não mais do que um exemplo entre outros não deixa, com alguma regularidade, de ir aflorando no discurso público.

A verdade é que há, de facto, aspectos absolutamente singulares no Holocausto, como, nomeadamente: a decisão de exterminar, não apenas um grupo enquanto tal, mas também todos os seres humanos classificados como pertencentes a esse grupo, até ao último; a centralidade do anti-semitismo para a ideologia nazi, que leva a que o extermínio se processe para além de toda a racionalidade político-militar (pense-se na formidável logística necessária para assegurar o transporte dos deportados, quando, a partir de 1943, justamente o momento em que se intensificam as deportações, são crescentes as dificuldades na área do transporte militar); a dimensão industrial do genocídio, traduzida na organização logística que referi e na planificação eficaz do extermínio em massa, marcada por uma racionalidade tecnológica que vai desde as câmaras de gás aos crematórios, passando pelo aproveitamento integral dos despojos dos corpos das vítimas como matéria-prima. ${ }^{2}$

Esta singularidade sinaliza, efectivamente, um exemplo consumado de violência absoluta, e é enquanto tal que o Holocausto se oferece como paradigma. Afirmar a singularidade do genocídio nazi não significa, assim, que ele não possa sofrer comparação com outros eventos históricos igualmente extremos - na verdade, é a própria singularidade que suscita a relevância da comparação, que não só é legítima como necessária. ${ }^{3}$ Acresce o aspecto essencial de que não é apenas o carácter único dos factos em si, mas, do mesmo passo, a relevância do trabalho de memória a que deu origem que funda o significado singular de Auschwitz. Como sublinha Helmut Dubiel (2003), o Holocausto constitui hoje em dia, sem dúvida, uma imprescindível metanarrativa para qualquer outro fenómeno de violência a larga escala. Mas isto significa que, ao mesmo tempo que mantém a sua singularidade histórica, o Holocausto não surge à consciência contemporânea simplesmente

\footnotetext{
${ }^{1}$ Sobre a "disputa dos historiadores", cf., nomeadamente, AAVV (1987), Evans (1990), Peacock (2001), AAVV (2006).

${ }^{2}$ Sobre a modernidade do Holocausto, veja-se o estudo já clássico de Zygmunt Bauman (1989). As teses centrais de Bauman estão já prefiguradas nos estudos, insuficientemente divulgados, de H. G. Adler (cf., por exemplo, 1958).

${ }^{3}$ Paul Gilroy, por exemplo, entre outros, tem vindo a insistir na necessidade de desenvolver uma perspectiva comparatista entre a teoria pós-colonial e a teoria do Holocausto (Gilroy, 2000).
} 
como um acontecimento localizado no passado, mas como algo que se mantém presente. Esta presentificação é resultado de um longo processo que se inicia, no essencial, apenas nos anos sessenta do século passado e em que, muito mais do que o trabalho da história, é o trabalho da memória que desempenha um papel decisivo. É este o ponto central sobre que gostaria de reflectir neste texto - o lugar que o Holocausto ocupa na consciência contemporânea não deriva simplesmente do facto de representar um conjunto de factos históricos marcados pela singularidade de uma violência absoluta, antes se deve à profundidade do trabalho da memória que lhe está associado. Uma profundidade baseada num novo paradigma do testemunho que, entre outros aspectos, questiona radicalmente o papel da vítima e a concepção da vítima e que constitui hoje uma formação discursiva extremamente vigorosa nas suas múltiplas ramificações transgeracionais.

No longo ensaio Die Schuldfrage (O problema da culpa), publicado pouco depois do final da Segunda Guerra Mundial, em 1946, e hoje talvez um tanto esquecido (Jaspers, 1987), o filósofo alemão Karl Jaspers ${ }^{4}$ estabelece algumas definições que continuam a parecer-me pertinentes e que ajudarão à minha reflexão. Jaspers toma como ponto de partida a recusa de um conceito indiferenciado de culpa ou da atribuição de uma culpa colectiva ao povo alemão - o simples conceito de culpa colectiva é, a seus olhos, com boas razões, absurdo - e propõe, em vez disso, quatro conceitos que correspondem a quatro dimensões diferentes de um mesmo problema. Distingue, antes de mais, a culpa criminal, que tem origem numa responsabilidade por crimes objectivamente demonstrável através de prova e que pode ser objecto de sentença nos tribunais correntes. O segundo tipo de culpa - a culpa política, ocasionada por decisões de órgãos do Estado - só pode ser objecto das sanções impostas no quadro de uma situação dominada pelos vencedores. Isto é, numa situação de derrota, pode ocorrer a tipificação, por parte das potências vencedoras, de um quadro jurídico novo que permita a criminalização de actos tradicionalmente fora da alçada dos tribunais. Foi justamente o que aconteceu com o tribunal de Nuremberga, cujo feito marcante foi, como é sabido, o estabelecimento do conceito de crime contra a humanidade. A definição da culpa política, no sentido de Jaspers, permitiu, assim, criar um precedente jurídico de importância decisiva.

\footnotetext{
${ }^{4}$ Pelo facto de a mulher ser considerada judia, Jaspers foi afastado da universidade em 1937 e ostracizado pelos nazis, tendo o casal vivido até 1945 sob a ameaça permanente da deportação. No seu ensaio, contudo, ele não se arroga uma posição de exterioridade nem o papel de vítima, antes assume plenamente a perspectiva de alguém que não pode nem quer eximir-se a uma responsabilidade colectiva.
} 
Em terceiro lugar, Jaspers define o conceito de culpa moral. Esta tem que ver com a responsabilização ética pela participação em acções criminosas, mesmo que dessa participação não resulte uma responsabilidade criminal (tipicamente, o cumprimento forçado de ordens a que o sujeito não pôde eximir-se). Esta dimensão da culpa tem que ver com a consciência individual, o tribunal é o da consciência de cada um. Por fim, Jaspers define um quarto conceito, o de culpa metafísica. Esta delimita uma noção de responsabilidade que é independente de qualquer acção ou omissão por parte do sujeito, já que alude à responsabilidade que todo o ser humano assume relativamente à violência exercida sobre um qualquer outro ser humano. Trata-se, pois, de um princípio ético fundamental que abrange toda a humanidade e se estende às gerações seguintes, não podendo, por definição, prescrever. Apesar da tonalidade religiosa que, sem dúvida, a fundamentação de Jaspers dá a este conceito, ele parece-me de uma relevância capital para o nosso presente, já que aponta para um princípio ético elementar de respeito pelos direitos humanos, a única base possível para uma ética de alcance universal nos nossos dias. ${ }^{5}$

É sabido que, na Alemanha, ${ }^{6}$ a perseguição criminal dos crimes nazis apenas veio a ter lugar num momento relativamente tardio, a partir de inícios dos anos sessenta. Os julgamentos de Nuremberga tinham estabelecido um novo paradigma do direito internacional, mas o advento da Guerra Fria cedo levou a uma política de restauração e ao reforço de um curso político conservador que relegou para um lugar secundário da consciência pública alemã a questão do recente passado nazi. Só em 1958 foi criado, na cidade de Ludwigsburg, um órgão central com a missão de instruir processos de acusação contra criminosos nazis, a Repartição Central das Administrações Judiciais Estaduais para a Investigação dos Crimes Nacional-Socialistas ("Zentrale Stelle der Landesjustizverwaltungen zur Aufklärung nationalsozialistischer Verbrechen”). O trabalho desenvolvido por esta Repartição Central, criada especificamente para investigar crimes cometidos fora do território alemão e que, por isso, tinham escapado até então à jurisdição dos tribunais da República Federal da Alemanha, veio a ter enorme importância, apesar de, ao longos dos anos, ter tido de enfrentar muitos obstáculos - logo de início, por exemplo, o burgomestre de Ludwigsburg, Anton Saur, opôs-se violentamente, por receio de que o novo órgão de investigação judicial viesse a dar "mau nome" à cidade. Apesar disso, a actividade

\footnotetext{
${ }^{5}$ Para uma discussão da questão da culpa alemã em Jaspers e Hannah Arendt, cf. Schaap (2002).

${ }^{6}$ Refiro-me à República Federal da Alemanha, deixando de lado a República Democrática Alemã e a Áustria, países em que o processo de confrontação com o passado tem outras especificidades, igualmente problemáticas.
} 
da nova repartição não tardou a dar frutos e, poucos anos volvidos, ganhou plena visibilidade pública com a realização do chamado "processo de Auschwitz" (1963-1965), contra responsáveis do campo de Auschwitz, o primeiro grande processo instruído no âmbito da "Zentrale Stelle", ao qual muitos outros se seguiriam.

Apesar da importância destes momentos de afirmação do poder judicial contra a lógica de desculpabilização virulenta em largos sectores da sociedade alemã, foram sempre muitas as limitações políticas à actividade desta repartição e é grande a desproporção entre o número de processos instruídos e o número de condenações efectivas (ainda por cima, muitas vezes, a penas reduzidas ou mesmo apenas simbólicas). Com efeito, de 106496 investigados no âmbito de cerca de 15000 processos (quase sempre, contra mais do que uma pessoa simultaneamente), apenas 6495 réus foram efectivamente condenados. Em certas áreas especialmente sensíveis - como, por exemplo, as relacionadas com o mito do não envolvimento do exército regular em acções criminosas $^{7}-$ a desproporção é ainda mais gritante. Assim, de cerca de 1000 processos instruídos contra membros da Webrmacht acusados de crimes de guerra, nem um único chegou à barra dos tribunais. ${ }^{8}$

Hoje em dia, por evidentes motivos geracionais, esta fase está praticamente terminada. Não é de prever que venham a ter lugar muitos mais processos contra criminosos nazis. O processo de John Demianiuk, guarda do campo de Sobibor, a decorrer presentemente em Munique, poderá bem ser o último, e poderá mesmo nem chegar ao seu termo, dada a idade avançada do réu, já com 89 anos à data do início do processo, em 30 de Novembro de 2009.

Fez-se então justiça? Na verdade, como é bom de ver, só em escala reduzida: muitos criminosos ficaram impunes e a reparação colhida pelas vítimas teria sempre que ser desproporcionadamente limitada - não só pela enormidade irreparável dos sofrimentos, mas também porque, como, entre outros, anota Shoshana Felman (2001), a jurisprudência corrente não está centrada na vítima, mas sim na reparação devida à sociedade - no espaço convencional do tribunal, o testemunho da vítima apenas é relevante na medida em que contribui para a formação da prova, todas as outras dimensões do testemunho são secundarizadas, com a consequência de que reviver o trauma

\footnotetext{
${ }^{7}$ Este mito desmoronou-se em definitivo a partir de meados dos anos 90, com a exposição sobre os crimes da Webrmacht organizada pelo Instituto de Ciências Sociais de Hamburgo e mostrada ao longo de vários anos, por entre grande controvérsia, em inúmeras cidades alemães e austríacas (Heer e Naumann, 1995; Heer, 2005).

8 Os dados sobre a "Zentrale Stelle" são retirados da página Web da instituição (http://www.zentrale-stelle.de). Ver também o informativo verbete correspondente da enciclopédia Wikipedia.
} 
não resulta num processo de libertação, mas, muitas vezes, numa nova penalização da vítima. Por outras palavras: no contexto do tribunal, a memória deverá servir apenas à reconstrução histórica, é subordinada à história e ao apuramento dos factos, acabando a testemunha por ser uma peça menor de uma máquina jurídica que a transcende inteiramente.

O conhecimento histórico acumulado ao longo de mais de 60 anos sobre os crimes nazis e, muito em particular, sobre o Holocausto é, como é bem sabido, enorme e, hoje em dia, virtualmente inabarcável. Pode dizer-se com segurança que o conhecimento histórico sobre o genocídio dos judeus pelos nazis e sobre o conjunto dos crimes nacional-socialistas contra a humanidade está definitivamente consolidado. Embora continuem a surgir inúmeros estudos históricos, nomeadamente de âmbito local, os factos essenciais estão mais do que estabelecidos e, com poucas excepções (como a da existência ou não de uma ordem escrita por Hitler na raiz da "solução final"), não suscitam especial controvérsia.

As questões que permanecem e permanecerão em aberto, as perguntas para as quais não haverá talvez nunca resposta satisfatória - e que, por isso, demarcam acerbamente os limites da teoria -, não são, pois, da ordem da averiguação dos factos nem da simples interpretação histórica, mas sim da ordem da memória e da pós-memória, isto é, da ordem de uma relação com o passado estruturada a partir do envolvimento presente de sujeitos concretos. ${ }^{9}$ Ao interrogar-se, num ensaio fundamental de 1998, sobre “A quem pertence Auschwitz?", Imre Kertész não hesita em dar logo de início uma resposta muito clara: pertence, não tanto à geração das vítimas, de cujas mãos cada vez mais debilitadas pela idade se vai pouco a pouco escapando, mas sim à geração seguinte e às que vierem depois. Mas Kertész não deixa também de acrescentar uma restrição igualmente clara: "enquanto essas gerações o reivindicarem" (2002: 145). Vemo-nos, assim, regressados a Jaspers e ao conceito de culpa metafísica. E somos levados de novo à pergunta que já atrás formulei: como é possível que Auschwitz possa representar, não um simples facto histórico, um acontecimento do passado, mas uma realidade sempre presente e, portanto, capaz de fundamentar paradigmaticamente uma ética dos direitos humanos para a actualidade?

\footnotetext{
${ }^{9} \mathrm{O}$ conceito de pós-memória foi introduzido por Marianne Hirsch no seu estudo sobre fotografia, narrativa e memória (Hirsch, 1997). Num ensaio recente, a autora define o conceito nos seguintes termos: “'Pós-memória' aponta para a relação da segunda geração com experiências marcantes, muitas vezes traumáticas, que são anteriores ao seu nascimento, mas que, não obstante, lhes foram transmitidas de modo tão profundo que parecem constituir memórias em si mesmas." (Hirsch, 2008: 103).
} 
A resposta a esta pergunta está, a meu ver, indissoluvelmente ligada à questão do testemunho. É conhecida a aporia do testemunho, suscitada, em 1986, por Primo Levi em I sommersi e $i$ salvati e retomada por Giorgio Agamben na sua reflexão fundamental sobre Auschwitz (Agamben, 1999; Vecchi, 2001). Escreve Levi, num passo muitas vezes citado: "a história dos Lager foi escrita quase exclusivamente por aqueles que [...] nunca os sondaram até ao fundo. [...] Os que o fizeram, os que viram a Górgone, não regressarem para falar disso, ou regressaram mudos." (Levi, 1989: 6 e 63-64). Isto é, a verdadeira testemunha, aquela que possui o conhecimento mais extremo e mais vivo, é aquela que, paradoxalmente, é incapaz de testemunhar.

Esta aporia, aparentemente insolúvel, não é, no entanto, entendida por Levi num sentido paralisante. Pelo contrário, ela aponta um sentido muito preciso à ética do testemunho, ao estabelecer os limites deste, mas de modo nenhum faz esquecer que a testemunha é também, etimologicamente, terstis, isto é, um terceiro, que esteve presente e pode também atestar a verdade dos factos. Tanto mais que, neste caso, o terceiro que testemunha pode falar também na primeira pessoa, por muito que o simples facto de ter sobrevivido lhe confira um estatuto que Levi aponta como problemático, já que, como ele não se cansa de insistir, a posse de alguns privilégios, mesmo mínimos, um grau, mesmo que ínfimo, de cumplicidade com os exterminadores, eram, por via de regra, condição de sobrevivência no implacável mecanismo dos campos. O que torna o testemunho ainda mais difícil, já que o estatuto de vítima recebe a ambiguidade de se ter sido também cúmplice, mesmo que numa escala infinitesimal, um problema entre todos perturbador que Levi aborda no capítulo "A zona cinzenta" de Os que sucumbem e os que se salvam. Neste capítulo encontram-se as seguintes observações sobre a possibilidade do testemunho dos raríssimos sobreviventes das equipas encarregadas do mais terrível trabalho do campo, o funcionamento dos crematórios:

De homens que experimentaram um tormento tão extremo, não pode esperar-se que deponham no sentido jurídico do termo, mas algo que é, simultaneamente, um lamento, uma imprecação, uma expiação e uma tentativa de se justificarem e reabilitarem a si próprios. Deveria esperar-se uma explosão libertadora e não uma verdade como a da face da Medusa. (Levi, 1989: 36)

Esta distinção de Levi entre o depoimento no sentido jurídico e o testemunho da vítima é essencial para entendermos de que modo é, justamente, uma acepção ampla do conceito de testemunho que subjaz à 
transformação do Holocausto num paradigma universal. O testemunho, lembra Levi repetidamente, deve ser lido "com um olho crítico" (ibid.: 6): a testemunha não é um historiador nem um filósofo (ibid:: 122) e, para o prisioneiro comum, o mecanismo dos campos era indecifrável no seu conjunto, já que o horizonte de observação ao seu alcance era, inevitavelmente, muito limitado (ibid: 24). A testemunha também não é, na maior parte dos casos, um herói, um ser excepcional, mas simplesmente alguém a quem uma conjunção de acasos permitiu sobreviver. Isto é, o valor do testemunho, a veracidade do testemunho, devem, sem dúvida, ser aferidos no plano da verdade histórica e da análise sociológica, mas o seu significado vai muito mais além: desde logo, o testemunho dá ao sobrevivente uma razão para viver, permite-lhe construir uma autoridade que o arranca ao simples estatuto de vítima e lhe possibilita a afirmação de uma identidade para além do trauma, dá-lhe, em suma, o estatuto de vencedor da guerra contra a memória inscrita em todo o sistema de extermínio do III Reich (ibid.: 18).

Dois marcos fundamentais do início dos anos sessenta assinalam a transição decisiva para um contexto em que se torna possível este modo de enunciação do testemunho: o processo de Adolf Eichmann em Jerusalém, em 1961, e o processo de Auschwitz, em Frankfurt am Main, entre 1963 e 1965. De facto, estes são dois momentos decisivos em que o silêncio da testemunha finalmente se rompe. Não porque anteriormente ela não tivesse falado; tinha-o feito, de muito diferentes maneiras, mas, e este é um dado recorrentemente referido, sem que tivesse quem estivesse interessado em ouvi-la, tanto na Europa como em Israel e ainda menos noutras partes do mundo. O grande momento público de julgamento dos responsáveis nazis, os processos de Nuremberga, só marginalmente tinha focado a perspectiva da vítima e, além disso, só marginalmente também tinha tocado a questão do Holocausto, vendo-a como um simples aspecto entre outros da Segunda Guerra Mundial, um aspecto terrível, sem dúvida, mas longe do significado de ruptura civilizacional que a reflexão posterior viria a atribuir-lhe. Quer isto dizer que, no período do pós-guerra, não existe um espaço público para o testemunho, isto é, as condições de enunciação dominantes são totalmente desfavoráveis à articulação da memória, num contexto público dominado pelo desejo de esquecimento.

Mas não se trata apenas da hostilidade do meio envolvente, trata-se também de uma outra questão não menos importante, o facto de que a experiência vivida dificilmente se deixa articular de imediato. É necessário um trabalho, necessariamente longo e difícil, de reconquista da possibilidade de expressão da memória. Robert Antelme, que, apesar de tudo, 
logo em 1947 tinha publicado L'espèce bumaine, um dos primeiros grandes testemunhos sobre o universo concentracionário, exprime esta questão com toda a crueza:

Trazíamos connosco a nossa memória, a nossa memória vivíssima, e sentíamos um desejo frenético de a dizer tal qual. [...] E, não obstante, desde os primeiros dias, parecia-nos impossível de eliminar a distância que descobríamos entre a linguagem de que dispúnhamos e esta experiência que, na maior parte, estávamos ainda a prosseguir no nosso corpo. [...] Mal começávamos a contar, sufocávamos. O que tínhamos a dizer começava a parecer inimaginável a nós próprios. Esta desproporção entre a experiência que tínhamos vivido e a narrativa que era possível extrair dela não fez senão confirmar-se de seguida. (Antelme, 2004: 9)

Não admira que seja apenas nos anos 60 que surgem ou que obtêm repercussão ampla narrativas centrais como $A$ longa viagem, de Jorge Semprun, Se isto é um homem, de Primo Levi, e muitas outras. E não admira que o processo de Adolf Eichmann em Jerusalém possa, também neste aspecto, ter constituído uma cesura decisiva no contexto da confrontação com o Holocausto (Levi e Rothberg, 2003). Num texto em que faz uma relevante apreciação crítica da análise de Hannah Arendt em Eichmann em Jerusalém, o seu controverso relato sobre "a banalidade do mal" (Arendt, 1990), Shoshana Felman sublinha lapidarmente o alcance desta cesura, justamente a partir da perspectiva do que poderá chamar-se a emancipação do testemunho. Emancipação porque o espaço do tribunal que julga Eichmann, ao dar, desta vez, maciçamente a voz às vítimas (mais de cem sobreviventes comparecem como testemunhas) e ao dar a essa voz uma absoluta centralidade, oferece, do mesmo passo, a possibilidade de encontrar um modo de enunciação público para uma memória mantida até então no espaço do privado. De modo muito sugestivo, Felman vê, assim, no tribunal um espaço de tradução, tradução da memória privada num discurso público, que permite ao sujeito que testemunha reconstruir nesse mesmo acto uma identidade para além do trauma.

Deste ponto de vista, o julgamento de Eichmann constitui um momento privilegiado de produção discursiva por parte de vozes até então silenciadas e excluídas, um momento de constituição de um discurso público do testemunho. Um discurso público que não deve ser concebido como um espaço monolítico, mas como uma densa rede em que o carácter irredutivelmente privado do testemunho individual pode confluir numa corrente discursiva em que o sujeito supera a solidão irreparável da memória do seu sofrimento, no momento em que encontra a possibilidade de a traduzir e, 
deste modo, partilhar na linguagem de uma experiência colectiva. É assim que, nas palavras de Shoshana Felman, o julgamento de Eichmann constitui um acontecimento revolucionário:

É esta transformação revolucionária da vítima que faz a sua história acontecer pela primeira vez e acontecer como um acto jurídico de autoria da história.

(Felman, 2001: 320)

Este acto de autoria constitui um exercício da memória que não está virado para o passado, para a reconstrução do passado, mas para a construção de uma identidade no presente e no futuro, uma identidade que altera radicalmente o estatuto da vítima. Trata-se de um acto que torna, literalmente, o mundo vivível. De facto, como, entre outros, referem Semprun (1995: 19) e Kertész (2002), referindo-se implicitamente ao muito discutido veredicto de Adorno sobre o carácter bárbaro de toda a poesia que pudesse escrever-se depois de Auschwitz, a questão principal não está no facto de a vida nos campos não poder ser representada, mas, sim, no facto de ela não poder ser vivida. Pelo contrário, é, justamente, o acto de representação - e Kertész vai ao ponto de considerar que "o campo de concentração só é concebível na forma da literatura, não é concebível como realidade”, mesmo quando se tratou de uma realidade que o próprio viveu (2002: 146) -, é a afirmação prática da possibilidade da representação que permite a simples existência de um futuro, que torna vivível o mundo depois de Auschwitz. No contexto do processo de Eichmann, tal como no processo de Auschwitz em Frankfurt am Main, a transformação do tribunal criminal num espaço de ressonância e de construção colectiva do universo do testemunho tem um significado especial..$^{10}$ Como escreve ainda Shoshana Felman:

Para que o mundo pudesse ser vivível depois do Holocausto, era necessário articular juridicamente uma narrativa humana da catástrofe e da devastação passadas e combiná-la com futuras normas da lei. (Felman, 2001: 235)

Um dos capítulos mais marcantes de I sommersi e $i$ salvati diz respeito às estruturas de comunicação e de incomunicação nos campos. Muitas vezes, refere Primo Levi, a possibilidade de sobrevivência estava desde logo perdida pela incapacidade de comunicar e, assim, aceder rapidamente à posse

${ }^{10}$ No seu drama-documento Die Ermittlung (A investigação), de 1965, que tematiza o processo de Auschwitz através de uma montagem de passos das actas do tribunal, o dramaturgo alemão Peter Weiss captou esse significado de modo particularmente agudo. 
de informação vital. Muitos dos prisioneiros não falavam alemão e o campo era uma Babel em que se cruzavam miríades de línguas e dialectos. Nem a linguagem do companheiro do lado nem a dos opressores eram, muitas vezes, compreendidas, tanto mais que a linguagem dos opressores constituía um discurso com regras próprias, a linguagem da violência analisada por Viktor Klemperer (1991), que mesmo os prisioneiros falantes de alemão tinham que aprender. Isto é, a capacidade de tradução constituía um requisito elementar para a sobrevivência pessoal. Mas, neste caso, o espaço da tradução não vai além dessa função de sobrevivência, não representa um enriquecimento das possibilidades do sujeito para além do mais imediato. Trata-se de uma tradução instrumental, em que a linguagem está reduzida a uma tarefa puramente funcional. Em contrapartida, o testemunho oferece o espaço de recuperação da linguagem e, também por isso, de geração de comunidade e de aquisição de autoridade. É como autor ou como autora, como alguém capaz de produzir um discurso da memória susceptível de se articular com um discurso colectivo e de afirmar uma posição própria no âmbito desse discurso, que o sobrevivente conquista para si a possibilidade, mesmo que precária, de futuro. ${ }^{11}$

Os vários projectos de constituição de arquivos visuais - entre outros, The Fortunoff Video Archive for Holocaust Testimonies da Universidade de Yale ou, mais recentemente, a Survivors of the Shoah Visual History Foundation, fundada por Steven Spielberg - constituem, hoje em dia, instrumentos fundamentais da criação de um espaço público do testemunho (Assmann, 2006). Mais ainda do que o registo escrito, o registo em vídeo, pela sua dimensão performativa, produz um acontecimento que permite comunicar não apenas através das palavras, do que é dito, mas também do que, visivelmente, fica por dizer naquilo que é dito, aquilo em que a experiência do Holocausto excede as possibilidades da linguagem. Tais arquivos, tal como toda a imensa massa testemunhal produzida sobretudo desde os anos 60, são instrumentos fundamentais de construção da pós-memória, enquanto possibilidade de participação naquilo que não se viveu. Como afirma Kertész, Auschwitz pertence hoje em dia às gerações seguintes. A tarefa ética que incumbe a estas é a de manter presente a vibração da memória, manter viva a ressonância dos testemunhos do modo mais paradigmático de violência absoluta no século Xx - uma ressonância que talvez produza outras e melhores condições para ouvir as vítimas das muitas outras violências desse século, e de todos os outros.

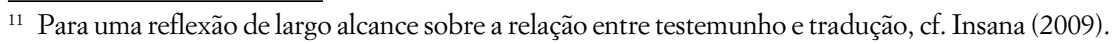




\section{Referências bibliográficas}

AAVV (1987), 'Historikerstreit'. Die Dokumentation der Kontroverse um die Einzigartigkeit der nationalsozialistischen Judenvernichtung. München: Piper.

AAVV (2006), "The Historikerstreit Twenty Years On", German History, 24(4), 587-607.

Adler, H. G. (1958), "Ideas toward a Sociology of the Concentration Camp", The American Journal of Sociology, 63(5), 513-22.

Agamben, Giorgio (1999), Ce qui reste d'Auschwitz. L'archive et le témoin. Homo Sacer III. Trad. Pierre Alferi. Paris: Rivages.

Antelme, Robert (2004), L'espèce bumaine. Paris: Gallimard.

Arendt, Hannah (1990), Eichmann in Jerusalem. Ein Bericht von der Banalität des Bösen. Reclam: Leipzig.

Assmann, Aleida (2006), "History, Memory, and the Genre of Testimony", Poetics Today, 27(2), 261-73.

Bauman, Zygmunt (1989), Modernity and the Holocaust. Oxford: Polity Press.

Diner, Dan (1988), Zivilisationsbruch. Denken nach Auschwitz. Frankfurt am Main: Fischer.

Dubiel, Helmut (2003), "The Remembrance of the Holocaust as a Catalyst for a Transnational Ethic”, New German Critique, 90, 59-70.

Evans, Richard J. (1990), Im Schatten Hitlers? Historikerstreit und Vergangenheitsbewältigung in der Bundesrepublik. Frankfurt am Main: Suhrkamp.

Felman, Shoshana (2001), "Theaters of Justice: Arendt in Jerusalem, the Eichmann Trial, and the Redefinition of Legal Meaning in the Wake of the Holocaust", Critical Inquiry, 27(2), 201-38.

Gilroy, Paul (2000), Between Camps. Nations, Cultures and the Allure of Race. London: Penguin.

Heer, Hannes (2005), Vom Verschwinden der Täter. Berlin: Aufbau Taschenbuch Verlag.

Heer, Hannes; Naumann, Klaus (orgs.) (1995), Vernichtungskrieg. Verbrechen der Webrmacht 1941-1944. Hamburg: Hamburger Edition.

Hirsch, Marianne (1997), Family Frames: Photography, Narrative, and Postmemory. Cambridge, MA: Harvard University Press.

Hirsch, Marianne (2008), "The Generation of Postmemory", Poetics Today, 29(1), 103-28.

Insana, Lina N. (2009), Arduous Tasks. Primo Levi, Translation, and the Transmission of Holocaust Testimony. Toronto/Buffalo/London: Toronto University Press.

Jaspers, Karl (1987), Die Schuldfrage. Zur politischen Haftung Deutschlands. München: Piper.

Kertész, Imre (2002), Eine Gedankenlänge Stille, während das Erschießungskommando neu lädt. Essays. Reinbek: Rowohlt.

Klemperer, Victor (1991), LTI. Lingua Tertii Imperii. Leipzig: Reclam. 
Levi, Neil; Rothberg, Michael (2003), "Auschwitz and the Remains of Theory: Towards an Ethics of the Borderland", symploke, 11(1-2), 23-38.

Levi, Primo (1989), The Drowned and the Saved. London: Abacus.

Peacock, Mark S. (2001), "The Desire to Understand and the Politics of Wissenschaft: An Analysis of the Historikerstreit", History of the Human Sciences, 14(4), 87-110.

Schaap, Andrew (2002), "Guilty Subjects and Political Responsibility: Arendt, Jaspers and the Resonance of the 'German Question' in Politics of Reconciliation”, Political Studies, 49(4), 749-66.

Semprun, Jorge (1995), A escrita ou a vida. Trad. Maria João Delgado e Luísa Feijó. Porto: Edições Asa.

Vecchi, Roberto (2001), "Barbárie e representação: o silêncio da testemunha”, in Sandra J. Pesavento (org.), Fronteiras do milênio. Porto Alegre: Editora da UFRGS, 71-94. 